\title{
Primary Staphylococcus aureus Pericarditis
}

\author{
Haya Aziz, MDCM, Marc Bienz, MD, MSc, Abdullah Esmaiel, MD, George Thanassoulis, MD, MSc
}

\begin{abstract}
About the Authors
Haya Aziz, are with the Division of Internal Medicine, McGill University Health Centre, Montréal, QC, Canada. Marc Bienz, are with the Division of Hematology, McGill University Health Centre, Montréal, QC, Canada. Abdullah Esmaiel and George Thanassoulis are with the Division of Cardiology, McGill University Health Centre, Montréal, QC, Canada. Corresponding Author: haya.aziz@mail.mcgill.ca

Submitted: March 17, 2019. Accepted: March 27, 2019. Published: May 1, 2020. DOI: 10.22374/cjgim.v15i2.361
\end{abstract}

\begin{abstract}
Bacterial pericarditis is a rare but fulminant disease that requires prompt diagnosis and management. It most commonly occurs from direct extension of an adjacent focus of infection or by hematogenous spread to the pericardium from more distant septic foci. Predisposing risk factors include immunosuppression, uremia, collagen vascular disease and thoracic surgery. We present the case of a 77-year-old gentleman with no previous pericardial disease who was diagnosed with primary Staphylococcus aureus pericarditis. The patient was treated with percutaneous pericardial effusion drainage and appropriate antibiotics resulting in complete resolution of his symptoms. This unusual case emphasizes that although it is frequently associated with significant morbidity and mortality, purulent pericarditis can present in a more indolent manner and in the absence of typical predisposing risk factors.
\end{abstract}

\section{Resume}

La péricardite bactérienne est une maladie rare mais fulgurante qui nécessite un diagnostic et une prise en charge rapides. Elle survient le plus souvent dans le prolongement direct d'un foyer infectieux adjacent ou par propagation hématogène au péricarde à partir de foyers septiques plus éloignés. Les facteurs de risque prédisposants sont l'immunosuppression, l'urémie, les maladies vasculaires du collagène et la chirurgie thoracique. Nous présentons le cas d'un homme de 77 ans, sans antécédents de maladie péricardique, chez qui on a diagnostiqué une péricardite primaire à Staphylococcus aureus. Le patient a été traité par un drainage percutané d’effusion péricardique et des antibiotiques appropriés, ce qui a permis de résoudre complètement ses symptômes. Ce cas inhabituel souligne que, bien qu'elle soit fréquemment associée à une morbidité et une mortalité importantes, la péricardite purulente peut se présenter de manière plus indolente et en l'absence de facteurs de risque prédisposants typiques.

A 77-year-old man presented with progressive dyspnea and pleuritic chest pain of recent onset that was relieved by leaning forward. His past medical history was notable for polymyalgia rheumatica treated with prednisone and poorly controlled type 2 diabetes mellitus (HbA1C 9.8\%). Physical exam was unremarkable. His electrocardiogram showed diffuse ST-segment elevation with ST-segment depression and PR elevation in lead
aVR. Transthoracic echocardiogram (TTE) revealed normal biventricular systolic function and an $8 \mathrm{~mm}$ circumferential pericardial effusion. Treatment with colchicine was initiated for idiopathic pericarditis.

The patient returned with worsening dyspnea and orthopnea. Repeat TTE showed pericardial thickening over the right ventricle, a $21 \mathrm{~mm}$ effusion with signs of elevated pericardial 


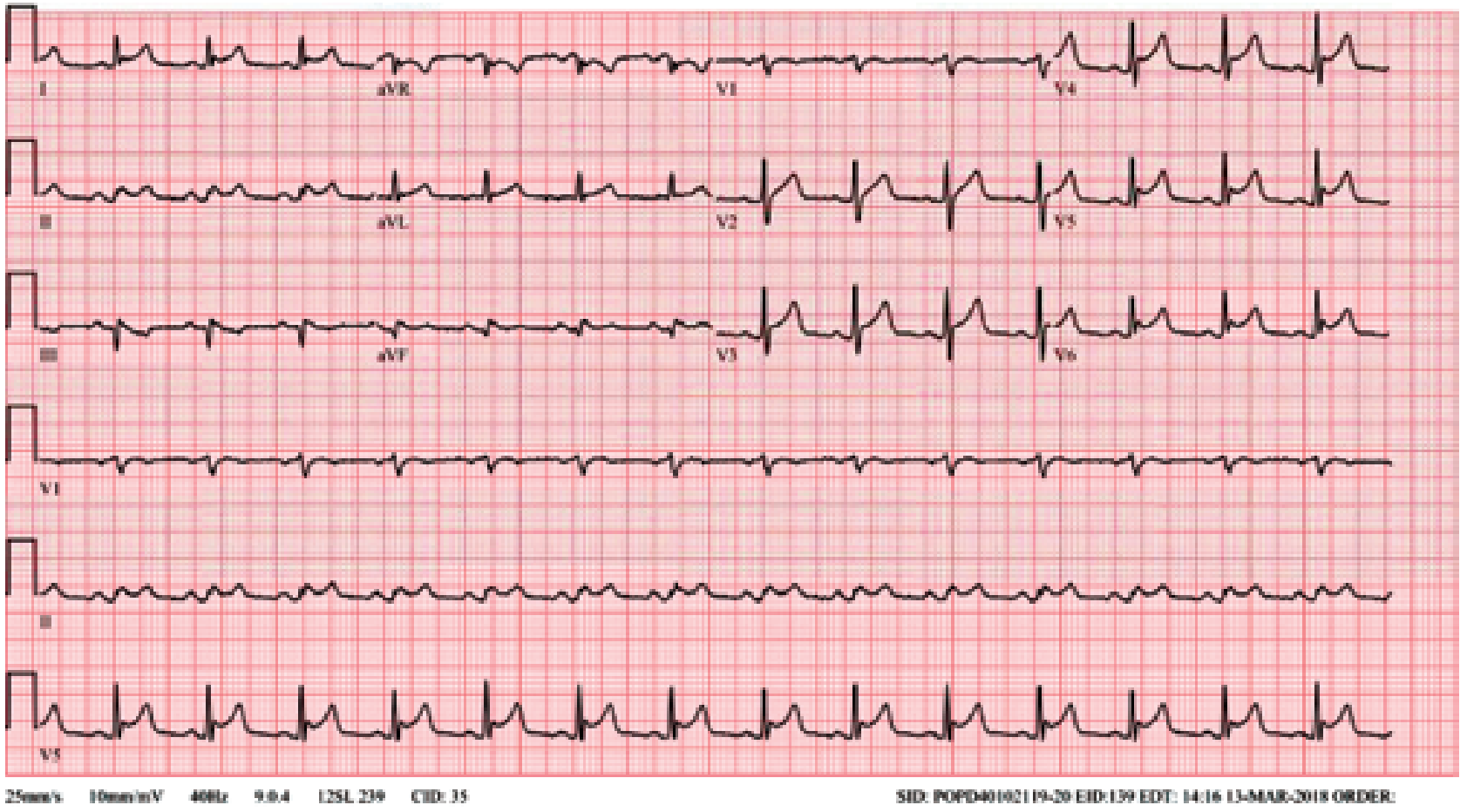

Figure 1. ECG at initial presentation demonstrating diffuse ST segment elevation and PR depression, with PR elevation and ST depression in AVR.

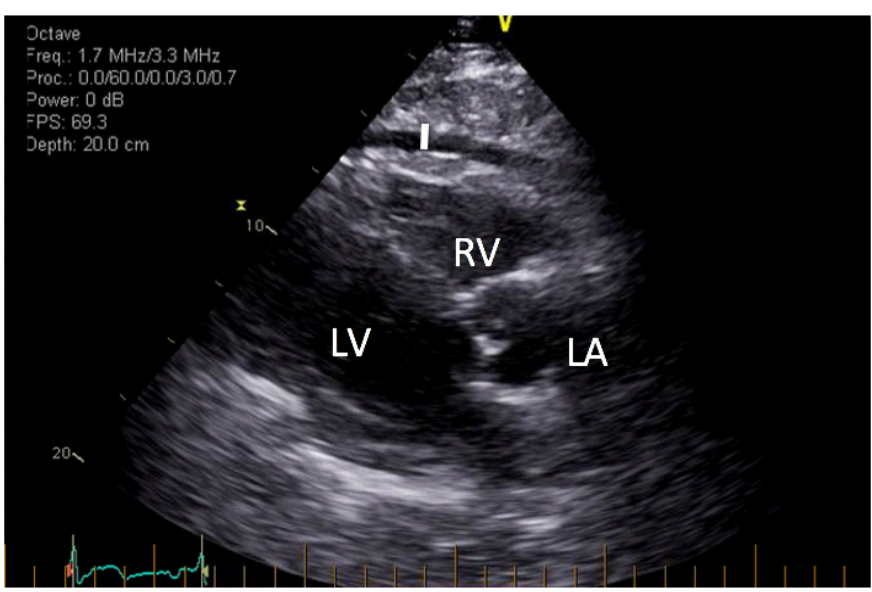

Figure 2A. Parasternal long-axis echocardiogram view showing an 8-mm pericardial effusion. $\mathrm{RV}=$ right ventricle; $\mathrm{LV}=$ left ventricle; $\mathrm{LA}=$ left atrium

pressure including interventricular dependence, diastolic expiratory reversal in the hepatic veins and a plethoric noncompliant inferior vena cava. He underwent pericardiocentesis with insertion of a pericardial drain. Analysis of the pericardial fluid and catheter tip revealed marked neutrophilia and growth of methicillin-sensitive Staphylococcus aureus. The diagnosis of purulent pericarditis was established. No clear entry site or

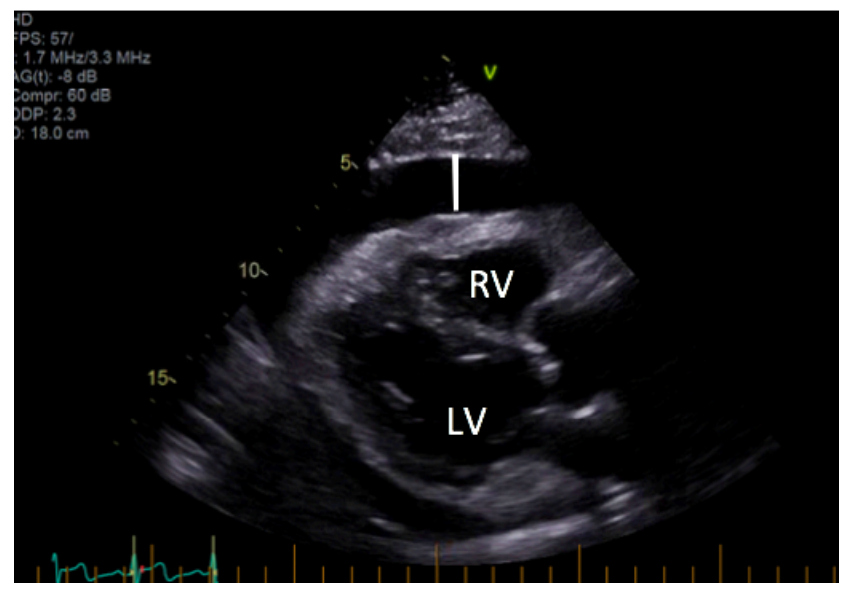

Figure 2B. Parasternal long-axis view showing thickening over the RV and a 21-mm pericardial effusion. $\mathrm{RV}=$ right ventricle; $\mathrm{LV}=$ left ventricle

source of seeding was identified other than a possible left lower lobe infiltrate on chest radiography. The patient was treated with intravenous cefazolin. At the 1-month follow up visit, he was asymptomatic with no evidence of constrictive hemodynamics on repeat imaging.

Bacterial pericarditis accounts for less than $1 \%$ of all causes of pericarditis. ${ }^{1}$ Most cases occur in the context of direct 
extension of infection from an intrathoracic site or by hematologic dissemination to the pericardium from another septic focus. ${ }^{2-4}$ Early pericardial drainage and appropriate antibiotic therapy are the cornerstones of management to prevent complications such as septic shock, cardiac tamponade and constrictive pericarditis. This case highlights that a high index of suspicion is required to diagnose bacterial pericarditis as it can present without common predisposing factors and in the absence of sepsis.

\section{References}

1. Adler Y, et al., 2015 ESC Guidelines for the diagnosis and management of pericardial diseases: The Task Force for the Diagnosis and Management of Pericardial Diseases of the European Society of Cardiology (ESC)Endorsed by: The European Association for Cardio-Thoracic Surgery (EACTS). Eur Heart J 2015;36(42):2921-64.

2. Boyle JD, Pearce ML, and Guze LB. Purulent Pericaditis: Review Of Literature And Report Of Eleven Cases. Medicine 1961;40(2):119-44.

3. Parikh SV, et al. Purulent pericarditis: report of 2 cases and review of the literature. Medicine (Baltimore) 2009;88(1):52-65.

4. Sagristà-Sauleda J, et al., Purulent pericarditis: Review of a 20-year experience in a general hospital. J Am Coll Cardiol 1993; 22(6):1661-65. 